\title{
MECHANISM OF ANTIFERTILITY ACTION OF LOW DOSES OF $\alpha$-CHLOROHYDRIN IN THE MALE RAT
}

\author{
B. H. VICKERY, G. I. ERICKSON AND J. P. BENNETT \\ Department of Reproductive Physiology, \\ Institute of Biological Sciences, Syntex Research, \\ Palo Alto, California 94304, U.S.A.
}

\section{(Received 16th April 1973)}

\begin{abstract}
Summary. The minimal effective daily oral dose of $\alpha$-chlorohydrin in the male Sprague-Dawley rat to prevent fertilization in the female following mating was found to be $2.5 \mathrm{mg} / \mathrm{kg} /$ day. The time to take effect and the time of recovery after withdrawal decreased and increased, respectively, as the dose was increased. With doses of up to $10 \mathrm{mg} / \mathrm{kg} /$ day, the sterility could not be accounted for on the basis of changes in the histology or weight of the male reproductive organs or accessory glands. The motility of spermatozoa recovered from the female tract the morning after mating was inhibited and, although normal numbers were recovered from the uterus, very few had entered the oviducts. When semen was collected from the uterus of a female 3 to $4 \mathrm{hr}$ after mating with a treated male and transferred directly into the ovarian bursa of an unmated female, the spermatozoa were capable of fertilization. Semen from untreated males, transferred in the same fashion, caused acceleration of egg transport in the oviducts which was not observed with the semen from treated males. Inhibition of sperm transport is assumed to be a major factor in prevention of fertilization and may, at least in part, be mediated through a change in the constituents of semen of treated males. The disparate effect on egg transport, implying effects on oviducal musculature, suggests the involvement of prostaglandins or similar smooth muscle stimulants in the mechanism.
\end{abstract}

\section{INTRODUCTION}

Previous studies of the antifertility action of $\alpha$-chlorohydrin (3-chloro-1,2propanediol, U-5897) have shown it to be effective in preventing pregnancy in the female rat, guinea-pig and monkey when administered orally to their male coital partners (Ericsson \& Baker, 1970; Kirton, Ericsson, Ray \& Forbes, 1970). Investigations into the mechanism by which this action is achieved have, however, been contradictory in their findings. Ericsson (1968) observed no effect on sperm motility and concluded that the effect was mediated through interference with the sperm oxygen supply or an accumulation of metabolic wastes rendering the spermatozoa infertile. Coppola (1969) reported motility to be severely reduced and suggested that the compound acts as a metabolic 
antagonist in phospholipid synthesis by virtue of its structural similarity to glycerol. At high dose levels, Smojlik \& Chang (1969) observed that the compound inhibited epididymal sperm motility in vitro and spermiogenesis. They concluded that the effect is exerted on the vascular system of the testis and epididymis probably by inhibition of an oxidation-reduction system. Ericsson \& Connor (1969), using similar doses, reported the development of lesions in the caput epididymidis leading to sperm blockage of the ductuli efferentes and testicular swelling.

The present authors feel that the mechanism of action at the minimal effective dose level can only be explained by study of events occurring at that dose level. The present report, therefore, concerns investigations of the mechanism of action of $\alpha$-chlorohydrin with particular emphasis on the minimal effective antifertility dose level.

\section{MATERIALS AND METHODS}

Mature Sprague-Dawley rats were obtained and rested for 2 weeks before experiment, for adjustment from source to colony conditions. Males (300 to $350 \mathrm{~g}$ ) were caged individually and females (190 to $220 \mathrm{~g}$ ) in groups of five, in airconditioned quarters with controlled illumination of $14 \mathrm{hr}$ light $/ 10 \mathrm{hr}$ darkness, until required for experiment. Free access to food and water was allowed. In Exps 1 to 4, the lighting was consistent with normal diurnal rhythms but it was reversed in Exp. 5.

Experiment 1. Two female rats were placed with each male and were checked daily by vaginal lavage. The first day on which spermatozoa were found to be present was taken as Day 1 of pregnancy. On detection of mating, the female was removed and replaced with a fresh female. All mated females were killed on Day 8 of pregnancy and the uteri were examined for implantation sites. The first 14 days of the experiment served to establish a pretreatment baseline for these rats.

On Days 15 to 35 of the experiment, the males received daily oral doses of either $\alpha$-chlorohydrin as a solution in propylene glycol or of the vehicle alone. The males were weighed three times weekly throughout the experiment. On Day 36 of the experiment, the males were killed and the testes, seminal vesicles and ventral prostate were dissected free. After weighing to the nearest $0.5 \mathrm{mg}$ on a torsion balance, the tissues were fixed in $10 \%$ neutral buffered formalin for histological preparation.

Experiment 2. A similarly timed study was conducted with the exception that on each of Days 1 to 5,8 to 12 and 15 to 23 of the experiment, one pro-oestrous female (nucleated epithelial cells in the vaginal lavage) was placed with each male overnight. On the following morning, each female was checked for mating by a further vaginal lavage and unmated animals were rejected. Mated females were killed on Day 2 of pregnancy and the reproductive tract from cervix to ovary was dissected out. The oviducts and uteri were separately flushed with isotonic saline to recover the eggs which were counted and examined for fertilization and morphological condition. The criterion of fertilization was cleavage to two or four equal-sized blastomeres each containing a nucleus. 
Daily dosage of the males with $\alpha$-chlorohydrin was maintained for investigation of the effects of chronic administration.

Experiment 3. Pro-oestrous female rats were caged overnight with males receiving chronic oral administration of $\alpha$-chlorohydrin or of the vehicle alone. On the following morning, unmated females were discarded. Mated females were killed and the uteri and oviducts were dissected free. One horn of the uterus and the contralateral oviduct were flushed with $0.5 \mathrm{ml}$ and $1.0 \mathrm{ml}$, respectively, of isotonic saline maintained at $37^{\circ} \mathrm{C}$ in a constant temperature water-bath. The flushings were immediately placed on a microscope slide, covered with a coverslip and scanned for the presence of motile spermatozoa. Every attempt was made to keep the time elapsing between flushing and scanning constant between animals. The remaining uterine horn and oviduct were flushed with $1.0 \mathrm{ml}$ and $0.1 \mathrm{ml}$, respectively, of $10 \%$ neutral buffered formalin to kill the spermatozoa rapidly without clumping. Aliquots of these flushings, diluted further with isotonic saline as necessary, were counted in a volume of $1.8 \mathrm{~mm}^{3}$ on a Neubauer brite-lite haemocytometer. From the counts obtained, the numbers of spermatozoa in the original flushing volume were calculated.

Experiment 4. Daily administration of $\alpha$-chlorohydrin or of the vehicle alone was maintained continuously for 4 months and then stopped. One week before cessation of treatment of males, two females were caged with each male and replaced with fresh females after mating. Mated females were killed on Day 8 of pregnancy and the uteri were examined for implantation sites. All males were killed 21 days after the last dose and testes, seminal vesicles, ventral prostates, epididymides and pituitaries were recovered, weighed, and fixed for histological preparation.

Experiment 5. After 2 weeks of acclimatization under reversed light-dark conditions, two pro-oestrous females were caged with each male over the 'dark period'. The mated females (spermatozoa in the vaginal lavage) were killed on Day 2 of pregnancy, the condition being confirmed by the recovery of twocell eggs from the oviducts. Males which mated on three consecutive occasions and were shown to have achieved successful impregnation were placed on experiment.

Oral administration of $2.5 \mathrm{mg} \alpha$-chlorohydrin $/ \mathrm{kg} / \mathrm{day}$ or vehicle alone was then instituted. Females in pro-oestrus or oestrus were selected by vaginal lavage, and their receptivity was confirmed by lordosis in the presence of a test male. Beginning 1 week after treatment and continuing daily until sufficient numbers of animals had been gathered, such selected females were caged individually with a treated male. The pairs were observed until an ejaculation was obtained from the male. The female was immediately removed and the time noted. Between 3 to $4 \mathrm{hr}$ after mating, the mated females were anaesthetized with ether and subjected to laparotomy to expose the uterine horns. Approximately $0.5 \mathrm{ml}$ isotonic saline maintained at $37^{\circ} \mathrm{C}$ was injected into each uterine horn, then aspirated and held at $37^{\circ} \mathrm{C}$ for $5 \mathrm{~min}$ before transfer to recipients. The incision in the donor rat was closed with silk suture (000 gauge) and the animal was allowed to recover. The recipient rats were selected in the same way as the donors, anaesthetized with Nembutal and two dorsolateral incisions were made to expose the oviducts. 
The ovarian bursa of the recipient rat was incised and an aliquot of the diluted semen recovered from the donor rat was placed at the opening of the fimbria. A single suture was used to close the peritoneal incision on each side and the skin apposed with a suture clip. The animal was allowed to recover and returned to the animal quarters.

The females were killed at 10.30 hours on the 2 nd day after the operation. Thus, the donors were killed approximately 45 to $47 \mathrm{hr}$ after mating and the recipients 41 to $44 \mathrm{hr}$ after the operation. The oviducts, together with a small cuff of uterus, were dissected free from fat and flushed with isotonic saline to recover the eggs, which were examined for evidence of fertilization. The criterion for fertilization was egg cleavage as described above, except that questionable eggs were further examined by staining with lacmoid specifically to demonstrate nuclear material in each blastomere (Yanagimachi \& Chang, 1961).

\section{RESULTS}

Experiment 1. The onset of antifertility activity demonstrated in mated females after oral administration of $\alpha$-chlorohydrin to their male coital partners

Table 1. Effect of daily oral administration of $\alpha$-chlorohydrin on the mating activity and fertility of male rats*

\begin{tabular}{|c|c|c|c|c|c|c|c|}
\hline \multirow{3}{*}{$\begin{array}{c}\text { Daily } \\
\text { dose } \\
(\mathrm{mg} / \mathrm{kg})\end{array}$} & \multicolumn{7}{|c|}{$\%$ Animals pregnant } \\
\hline & \multirow{2}{*}{$\begin{array}{c}\begin{array}{c}\text { No } \\
\text { treatment }\end{array} \\
\text { Day } 14\end{array}$} & \multicolumn{6}{|c|}{ Treatment } \\
\hline & & Day 15 & Day 16 & Day 17 & Day 18 & Day 19 & Day 22 \\
\hline $\begin{array}{r}\overline{0 \cdot 2} \\
1 \cdot 0 \\
2 \cdot 5 \\
5 \cdot 0 \\
10 \cdot 0 \\
25 \cdot 0\end{array}$ & $\begin{array}{c}100(3) \\
100(1) \\
100(3) \\
100(2) \\
80(3) \\
100(2) \\
100(3)\end{array}$ & $\begin{array}{r}100(1) \\
100(2) \\
100(4) \\
100(3) \\
80(5) \\
100(4) \\
100(1)\end{array}$ & $\begin{array}{r}100(1) \\
100(2) \\
-(0) \\
100(3) \\
100(3) \\
50(4) \\
14(7)\end{array}$ & $\begin{array}{r}100(2) \\
100(1) \\
80(5) \\
100(2) \\
100(4) \\
20(2) \\
0(3)\end{array}$ & $\begin{array}{r}100(3) \\
75(4) \\
100(3) \\
100(1) \\
0(1) \\
0(2) \\
17(6)\end{array}$ & $\begin{array}{r}67(3) \\
100(2) \\
67(3) \\
50(4) \\
0(1) \\
0(1) \\
0(3)\end{array}$ & $\begin{array}{c}100(5) \\
100(3) \\
0(3) \\
0(2 \\
0(3 \\
0(4)\end{array}$ \\
\hline
\end{tabular}

The number of females mated is given in parentheses.

* Five males per group.

(Table 1) was seen to vary directly with dose. Marked effects were shown 1 day after the commencement of treatment with $25 \mathrm{mg} / \mathrm{kg} /$ day, 2 days after 10 $\mathrm{mg} / \mathrm{kg} /$ day, and 5 days after $2.5 \mathrm{mg} / \mathrm{kg} /$ day. No significant effect on body weight was observed during the course of the experiment. At autopsy of the males 3 weeks after commencement of treatment, pituitary weight alone showed a significant deviation from that of the controls but only with doses of $2.5 \mathrm{mg} / \mathrm{kg} /$ day (Text-fig. 1). Histological examination of the recovered organs showed no gross changes except in the testes of rats receiving $25 \mathrm{mg} / \mathrm{kg} /$ day.

Experiment 2. Using a narrower dose range, daily investigation of the eggs recovered from the females mating with males treated with $\alpha$-chlorohydrin established that the cause of antifertility was an interference with fertilization (Table 2). 


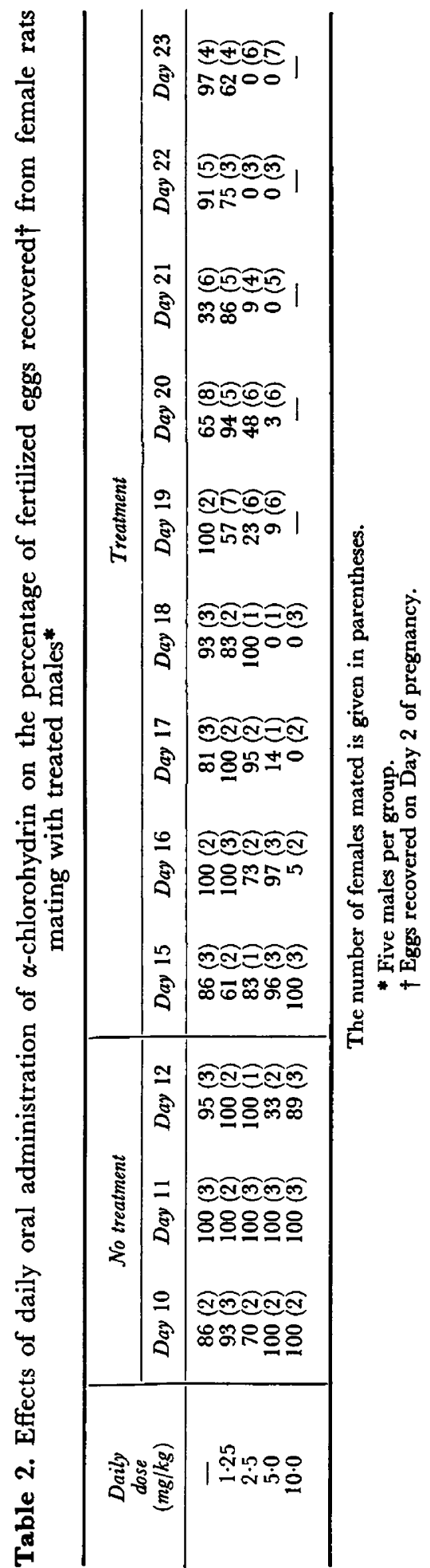


Experiment 3. Other females were mated with the males described in Exp. 2 and were used to investigate the distribution and motility of spermatozoa within the female reproductive tract following mating. A decrease in numbers of spermatozoa recovered from the oviducts was observed, which was directly related to the dose of $\alpha$-chlorohydrin administered to the males (Table 3). No change was observed in the numbers of spermatozoa recovered from the uterus compared to those from control matings. The motility of the spermatozoa recovered from either the uterus or the oviducts was decreased compared to

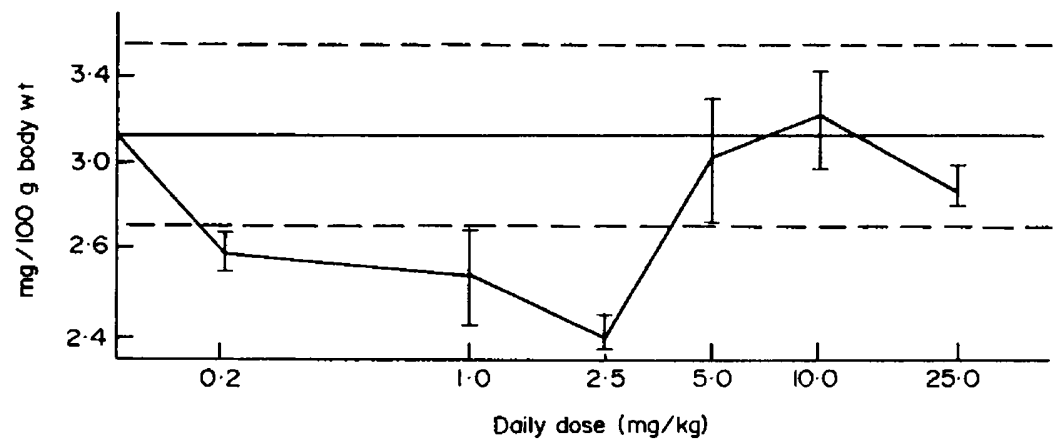

TEXT-FIG. 1. Effects of daily administration of $\alpha$-chlorohydrin for 3 weeks on pituitary weight in male rats. The horizontal line represents the mean pituitary weight of control rats and the dashed line on either side represents its S.E.

Table 3. Effect of daily oral administration of $\alpha$-chlorohydrin on the numbers and motility of spermatozoa recovered* from the reproductive tract of female rats mating with treated males

\begin{tabular}{c|c|cc|cc}
\hline $\begin{array}{c}\text { Dose given to males } \\
\text { (mg/kg/day) }\end{array}$ & $\begin{array}{c}\text { No. of } \\
\text { females } \\
\text { mated }\end{array}$ & $\begin{array}{c}\text { Mean no. of sperm. } \\
\text { recovered per rat } \\
\text { Oviduct }\end{array}$ & Uterus & $\begin{array}{c}\text { No. of animals } \\
\text { with motile sperm. } \\
\text { Oviduct }\end{array}$ & Uterus \\
\hline- & 10 & 500 & 394,450 & 1 & 5 \\
\hline $1 \cdot 25$ & 11 & 402 & 667,180 & 2 & 4 \\
$2 \cdot 5$ & 10 & 17 & 466,180 & 0 & 2 \\
$5 \cdot 0$ & 10 & 6 & 718,550 & 0 & 2 \\
$10 \cdot 0$ & 10 & 65 & 509,146 & 0 & 0 \\
\hline
\end{tabular}

* Recovery 09.00 to 10.00 hours on Day 1 of pregnancy.

control matings, again showing correlation with the dose level administered to the male.

Experiment 4 . Return of fertility after 4 months administration of $\alpha$-chlorohydrin was also directly related to dose. Complete return occurred by the 3rd day after the last dose of $2.5 \mathrm{mg} / \mathrm{kg} /$ day but took between 7 to 10 days after a dose of $10.0 \mathrm{mg} / \mathrm{kg} /$ day (Text-fig. 2). Unfortunately, all animals receiving $5.0 \mathrm{mg} / \mathrm{kg} /$ day died during the period of dosing so that return of fertility in this group could not be ascertained. The deaths in this group were completely unrelated to the compound under investigation. Apart from an increase in pituitary weight, no significant changes in the organ weights of the males dosed with $2.5 \mathrm{mg} / \mathrm{kg} /$ day were detectable at autopsy (Text-fig. 3). 


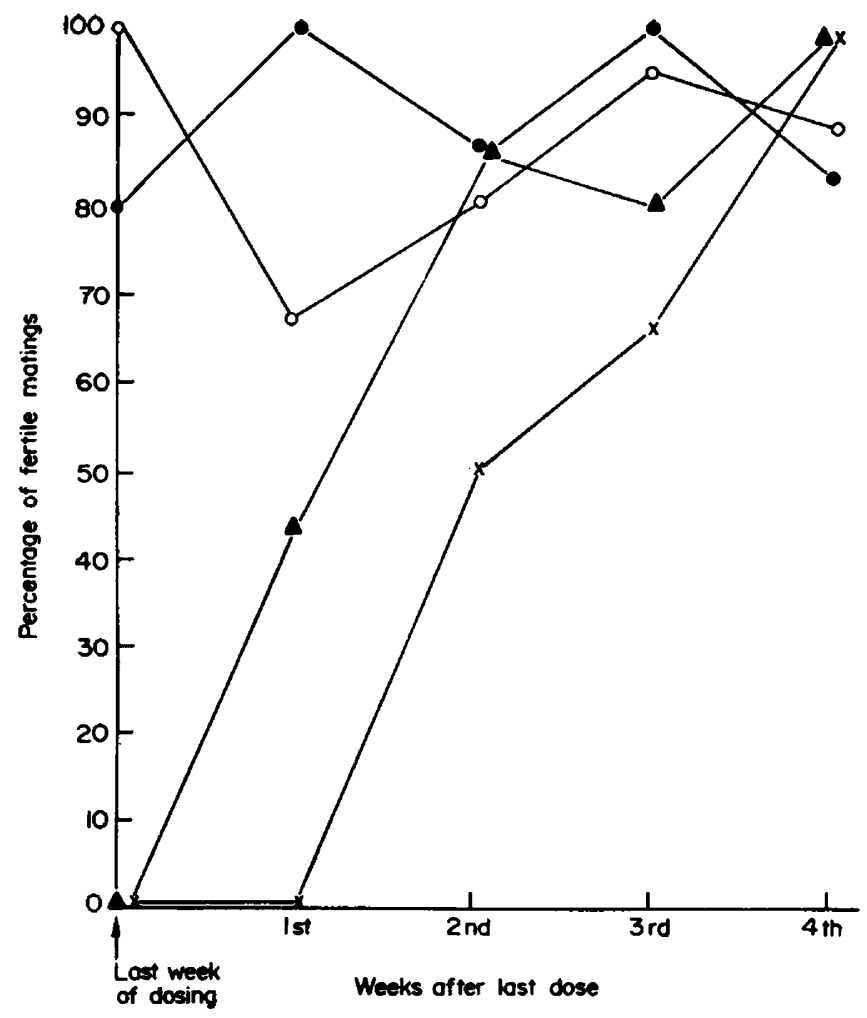

TEXT-FIG. 2. Return of fertility after termination of daily dosing for 4 months of male rats with $\alpha$-chlorohydrin. $\bullet$, Control (vehicle only); $0,1.25 \mathrm{mg} \alpha$-chlorohydrin/kg/day; $\Delta$, $2.5 \mathrm{mg} \alpha$-chlorohydrin/kg/day; $x, 10.0 \mathrm{mg} \alpha$-chlorohydrin/kg/day.
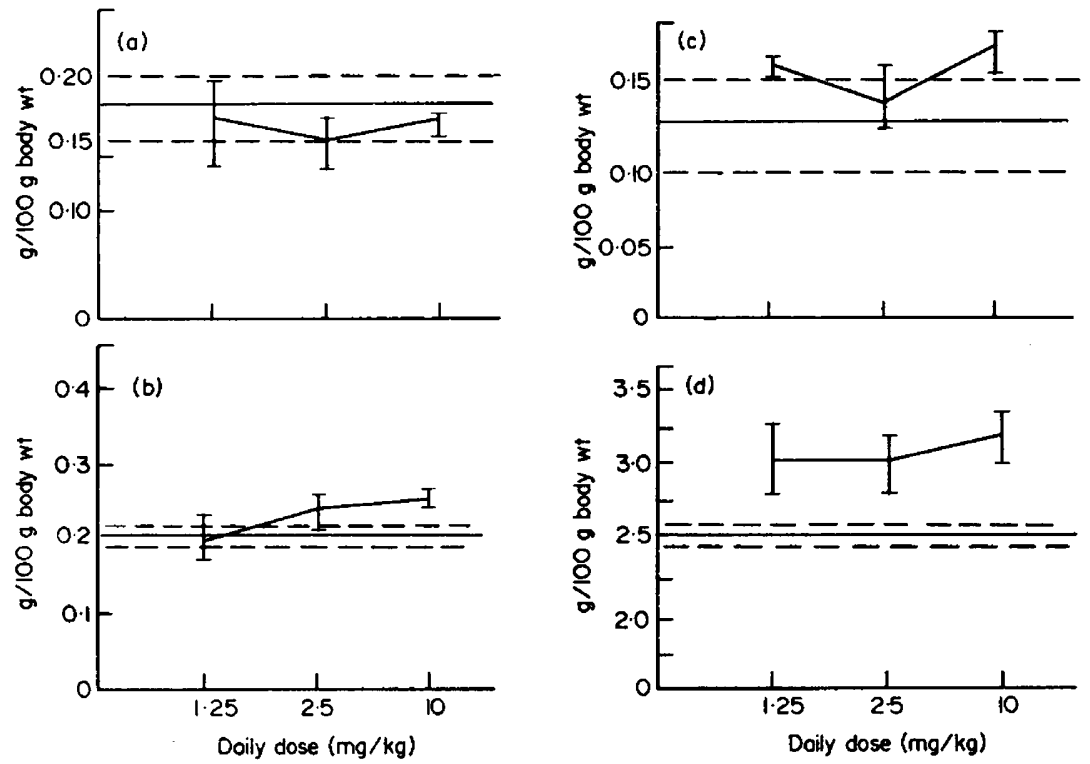

TexT-FIG. 3. Effects of daily dosing for 4 months with $\alpha$-chlorohydrin on the weights of various organs in male rats killed 4 weeks after the last dose. (a) Seminal vesicle and coagulating gland; (b) epididymis; (c) ventral prostate; (d) pituitary. Horizontal line represents the mean organ weight of control rats and the dashed line on either side represents its S.E. 
Experiment 5. The results of attempts to transfer spermatozoa from the uterus to the ovarian bursa are summarized in Table 4 . Although fertilization resulting from transfer of spermatozoa after control matings is low, illustrating the technical difficulties involved, some fertilizations did result from transfer after matings with males receiving $2.5 \mathrm{mg} / \mathrm{kg} /$ day. A further difference between semen from control and treated males was the effect on the rate of tubal transport of eggs in the recipient females. A mean egg recovery of 2.2 in recipients of control semen was contrasted with 5.9 in recipients of semen from treated males.

Table 4. Fertilizing ability of spermatozoa obtained from mating male rats treated with $\alpha$-chlorohydrin* as revealed by sperm transfer from uterus to ovarian bursa

\begin{tabular}{c|cc|cc|cc}
\hline \multirow{2}{*}{$\begin{array}{c}\text { Dose } \\
(\mathrm{mg} / \mathrm{kg} / \mathrm{day})\end{array}$} & $\begin{array}{c}\text { No. of animals } \\
\text { per group }\end{array}$ & \multicolumn{2}{|c|}{$\begin{array}{c}\text { Mean no. of } \\
\text { eggs recovered }\end{array}$} & \multicolumn{2}{c}{$\begin{array}{c}\% \text { Recovered eggs } \\
\text { fertilized }\end{array}$} \\
\cline { 2 - 7 } & Donor & Recipient & Donor & Recipient & Donor & Recipient \\
\hline- & 8 & 17 & 8.8 & 2.2 & 68 & 27 \\
\hline 2.5 & 8 & 24 & 8.5 & 5.9 & 0 & $8 \dagger$ \\
\hline
\end{tabular}

* Daily administration for not less than 1 week and not more than 3 weeks at time of mating.

$\dagger$ This represents fertilized eggs recovered from six of the twenty-four recipients.

\section{DISCUSSION}

The present investigations have established that $\alpha$-chlorohydrin achieves its sterilizing activity at the minimal effective antifertility dose level by prevention of fertilization in the female following mating. The number of days of treatment required to achieve this effect suggests (a) that the accumulative level of the compound has to exceed a certain threshold and (b) that the effect is exerted beyond the testis level, e.g., at the level of the epididymis and/or secretions of the accessory glands. Prevention of fertilization is mediated through a change in sperm transport within the female reproductive tract, which can be correlated with sperm motility and also with a muscle-stimulating property of the semen.

The minimal effective daily oral antifertility dose of $\alpha$-chlorohydrin in the male Sprague-Dawley rat was found to be $2.5 \mathrm{mg} / \mathrm{kg} / \mathrm{day}$. This contrasts with the finding of Ericsson \& Baker (1970) that 6 to $7 \mathrm{mg} / \mathrm{kg}$ (2 mg/rat) were required on a daily basis in their colonies of Spartan and Upjohn rats. The discrepancy is probably attributable to strain differences.

The time elapsing between commencement of treatment and achievement of male sterility was found to be directly related to dose. With levels of up to 10 $\mathrm{mg} / \mathrm{kg} / \mathrm{day}$, the sterility could not be accounted for on the basis of numbers of spermatozoa in the ejaculate, or by changes in the histology or weight of male reproductive organs or accessory glands. At $25 \mathrm{mg} / \mathrm{kg} /$ day, $\alpha$-chlorohydrin was shown to have antispermatogenic effects which were probably mediated through the lesions in the epididymis as demonstrated by previous workers (Ericsson \& Connor, 1969). A tenfold separation between antispermatogenic effects and minimal effective dose level has, however, been demonstrated. 
The correlation of antifertility effect with decrease in sperm motility in vivo is in direct contrast to previous results in vivo (Ericsson, 1968) but does substantiate the results of studies in vitro (Coppola, 1969; Smojlik \& Chang, 1969). The decrease in sperm motility has been suggested as due to competition of $\alpha$-chlorohydrin in epididymal phospholipid synthesis because of its structural similarity to glycerol (Coppola, 1969). The results of more recent studies in which other competitors, in particular glycidol, have been shown to exert the same male-sterilizing activity (Ericsson \& Youngdale, 1970) lend weight to this explanation.

The further observations that the vasa deferentia and epididymides of rats treated with $\alpha$-chlorohydrin, and the vasa deferentia of similarly treated monkeys, show increased zinc uptake have also been implicated in the mechanism of suppression of sperm motility by this compound (Setty, Kar, Roy \& Chowdhury, 1970; Gunn \& Gould, 1972). It was suggested that the normal depletion of zinc in the spermatogenic pathway was impeded and/or too high a concentration of zinc in the seminal fluid blocks the expenditure of energy in the spermatozoa required for the final surge of motility for traversing the oviducts and penetration of the ovum.

The finding that recoveries of spermatozoa from the uterus are not correlated with the dose-related fall in tubal recoveries is in agreement with the demonstration by Blandau $(1941,1945)$ that entry of spermatozoa into the uterus is not dependent on intrinsic motility but is a mechanical effect of direct intrauterine insemination. The remarkable correlation between motility of spermatozoa in utero and the numbers of spermatozoa recovered from the oviducts would, however, suggest that sperm motility plays an essential rôle in sperm transport within the female tract. This conflicts with previous reports (Marcus, 1965) which concluded that even dead spermatozoa were capable of transportation from uterus to oviduct in the rat. An explanation for the apparent disagreement may be gained from the results of studies of the transfer of spermatozoa. It was apparent that the semen from control animals affected the rate of egg transport in recipient females, whereas that from treated males did not. If this response was due to stimulation of muscular activity in the oviducts, then some factor present in normal semen must be missing from semen of treated males. Prostaglandins have been reported to be present in the semen of many species and are produced by the seminal vesicles. Although a literature survey fails to reveal any such investigations in the rat, unpublished work by the present authors comparing semen from intact rats and those from which the seminal vesicles had, been removed suggests that similar substances are produced in the rat. Prostaglandins from other species have been shown to affect ovum transport in the rat and rabbit (Nutting, 1969; Chang \& Hunt, 1972). Thus, the explanation for interference with sperm transport may be compounded of lack of both sperm and uterine motility. The results of sperm transfer studies suggest that, even though fertilization and/or the capacitation of the spermatozoa may be affected, the spermatozoa are still capable of fertilization, so that inhibition of transport must be a major factor in prevention of fertilization.

These findings are, therefore, in agreement with those of previous investi- 
gations in which inhibition of sperm motility has been implicated but also suggest that the composition of the semen is changed in some way. The change may be mediated directly or through the pituitary. In view of the changes in pituitary weight with administration of $\alpha$-chlorohydrin, further investigation of the latter possibility may prove rewarding.

\section{ACKNOWLEDGMENTS}

The authors gratefully acknowledge the skilled technical assistance of Mrs Brenda Trimble, Mr Henry Carter, Jr and Mr William Briones in these studies.

\section{REFERENCES}

BLANDAU, R. J. (1941) A technique for the artificial insemination of the white rat. F. Lab. clin. Med. 26, 1361.

BLANDAU, R. J. (1945) On the factors involved in sperm transport through the cervix of the white rat. Am. 7. Anat. 77, 253.

Chang, M. C. \& Hunt, D. (1972) Effect of prostaglandin $F_{2 x}$ on the early pregnancy of rabbits. Nature, Lond. 236, 120.

Coppola, A. J. (1969) An extragonadal male antifertility agent. Life Sci. 8, 43.

Ericsson, R. J. (1968) U-5897: A post-testicular antifertility drug. Proc. 1st Ann. Meeting Soc. Study Reprod., Nashville, Tenn.

ERICsson, R. J. \& BAKER, V. F. (1970) Male antifertility compounds: biological properties of U-5897 and U-15,646. 7. Reprod. Fert. 21, 267.

ERicsson, R. J. \& Connor, N. D. (1969) Lesions of the rat epididymis and subsequent sterility produced by U-5897 (3-chloro-1,2-propanediol). Proc. 2nd Ann. Meeting Soc. Study Reprod., Davis, California.

Ericsson, R. J. \& Youngdale, G. A. (1970) Male antifertility compounds: structure and activity relationships of U-5897, U-15,646 and related substances. F. Reprod. Fert. 21, 263.

GunN, S. A. \& Gould, T. C. (1972) The role of zinc in the post testicular antifertility action of monochlorhydrin. Proc. Soc. exp. Biol. Med. 141, 639.

Kirton, K. T., Ericsson, R. J., Ray, J. A. \& Forbes, A. D. (1970) Male antifertility compounds: efficacy of U-5897 in primates (Macaca mulatta). F. Reprod. Fert. 21, 275.

Marcus, S. L. (1965) The passage of rat and foreign spermatozoa through the utero-tubal junction of the rat. Am. 7. Obstet. Gynec. $91,985$.

Nurring, E. F. (1969) Antifertility activity of prostaglandin $\mathrm{E}_{2}$ in hamsters, rabbits, and rats. Proc. 2nd Ann. Meeting Soc. Study Reprod., Davis, California.

Setty, B. S., Kar, A. B., Roy, S. K. \& Chowdhury, S. R. (1970) Studies with sub-toxic doses of $\alpha$-chlorohydrin in the male monkey (Macaca mulatta). Contraception, 1, 279.

Smojlik, E. \& Ghang, M. G. (1969) Antifertility activities of U-5897 (3-chloro-1,2-propanediol) on male rats. Proc. 2nd Ann. Meeting Soc. Study Reprod., Davis, California.

Yanagimachi, R. \& Chang, M. C. (1961) Fertilizable life of golden hamster ova and their morphological changes at the time of losing fertilizability. F. exp. Zool. 148, 185. 